\title{
ANÁLISE DOS PROCESSOS DE COMUNICAÇÃO EM PROJETOS COM EQUIPES VIRTUAIS
}

\author{
Marciano Felipe Sehn, UFPR, marciano.sehn@gmail.com \\ Ricardo Mendes Junior, UFPR, mendesjr@ufpr.br
}

Este resumo apresenta uma breve descrição do trabalho de dissertação apresentado e defendido no Programa de pós-graduação em Engenharia de Produção da Universidade Federal do Paraná. Introdução: a globalização e as transformações nos meios de comunicação resultantes dela tornaram possível o desenvolvimento de uma nova forma de trabalho: o trabalho com equipes virtuais. Projetos com equipes virtuais possuem grande potencial na redução de custos para a empresa, permitindo manter um time altamente especializado, mesmo com restrições geográficas e de tempo. A comunicação nesse tipo de equipe é um fator altamente crítico na interação desses indivíduos, pois os contatos face-a-face são reduzidos, quando não, inexistentes. Objetivo: tem-se como objetivo deste trabalho o de analisar o processo de comunicação entre os integrantes de equipes virtuais de projetos. Método/Abordagens: a pesquisa possui uma abordagem qualitativa, caracterizando-se como exploratória em relação ao objetivo, tendo como instrumento o estudo de casos múltiplos, o primeiro representando o setor bancário, o segundo o ramo automobilístico e o terceiro um grupo de pesquisa. Resultados: como resultado, tem-se a obtenção de uma descrição de como ocorrem os processos de comunicação nos três casos estudados e do nível de concordância de cada equipe virtual aos processos por ela utilizados. Os resultados obtidos possibilitam identificar: que existe a falta de planejamento no gerenciamento das comunicações; que as equipes consideram necessário manter contato presencial para sanar falhas na comunicação virtual do projeto; que os elementos culturais não são considerados no momento de se estabelecer uma equipe virtual; e também que as equipes encontram alguma dificuldade em manter contato com pessoas de outros idiomas. Contribuições/Originalidade: a partir dos resultados, são apontadas algumas recomendações, entre as quais: buscar alternativas no contato pessoal entre os integrantes das Equipes Virtuais; incentivar a comunicação informal complementarmente à comunicação formal; observar as diferenças culturais entre os integrantes da equipe; promover uma cultura interna de incentivo à comunicação virtual; e dar maior importância à existência de plano de gerenciamento das comunicações.

Palavras-chave: Equipes Virtuais. Comunicação em Projetos. Gestão de Projetos. 